\title{
Women Satisfaction with Family Planning Services in Maternal and Child Health Centers, Assiut City, Egypt
}

\author{
Safaa Ahmed Mohamed ${ }^{1}$, Asmaa Ghareeb Mohamed ${ }^{1, *}$, Amal Fouad Arief $^{2}$ \\ ${ }^{1}$ Community Health Nursing, Faculty of Nursing, Assiut University, Egypt \\ ${ }^{2}$ Department of Obstetrics \& Gynecological Nursing, Faculty of Nursing, Assiut University, Egypt \\ *Corresponding author: asmaaghareeb75@yahoo.com
}

\begin{abstract}
Family planning (FP) is critical for the health of women and their families, and it can accelerate a country's progress toward reducing poverty and achieving development goals. FP is an important component of primary health care, maternal and child health. It is the means of planning families that want space according to choice and time to fit in with life decisions. Aim: This study aimed to assess satisfaction level of women attending Maternal and Child Health (MCH) centers with FP services. Methods: Descriptive cross-sectional study design was used. A total sample of 569 women was interviewed at four $\mathrm{MCH}$ centers covers Assiut city. Results: The findings revealed that the mean age of the respondents was $29.38 \pm 6.13,72.2 \%$ of them were from urban areas and $47.3 \%$ currently use a contraceptive method. A high satisfaction level with family planning services was noticed. Conclusion: significantly, the majorities of the clients was satisfied with the provided skills and counseling. It was approved that the most of $\mathrm{MCH}$ centers have good quality level in health services and facilities. Recommendation: Family planning providers require training to strengthen their communication skills so that they can meet their client's individual needs.
\end{abstract}

Keywords: family planning, women satisfaction, services, quality

Cite This Article: Safaa Ahmed Mohamed, Asmaa Ghareeb Mohamed, and Amal Fouad Arief, "Women Satisfaction with Family Planning Services in Maternal and Child Health Centers, Assiut City, Egypt." American Journal of Nursing Research, vol. 5, no. 3 (2017): 79-85. doi: 10.12691/ajnr-5-3-2.

\section{Introduction}

Family planning is highly beneficial to women's overall health, particularly in developing countries [12]. Family planning programs in developing countries have worked to increase the number of service delivery of points and expand into remote areas; however, to be effective, they must also address issues of service quality. Many family planning experts hypothesized that low-quality family planning services are a barrier to high contraceptive prevalence use [12].

Substantial increases in contraceptive use \& corresponding decline in fertility have been consistently observed throughout the developing world, although such changes have been limited in Sub- Saharan Africa than in other developing regions [4].

In last decades Egypt had suffered major socioeconomic consequences of overpopulation problem as a result of a high level of the birth rate. Overpopulation and unplanned population growth impede the socioeconomic development, hinder prosperity, and threatens the health status of community members [10].

The world population is growing by over 80 million people every year, by 2025 the world would contain over 8 billion people, 6.8 billion of them would live in developing countries, for Sub-Saharan Africa the rate of fertility will be 5.3 children for every woman [3].
Quality can refer to the technical quality of care to the nontechnical aspect of service delivery such as clients' waiting time and staff attitudes, and to programmatic elements such as policies, infrastructures, access, and management $[5,7]$. The quality of care can be measured from the perspectives of clients or providers or facility. Client satisfaction with services is a subjective way of measuring the quality of services; satisfied clients are more likely to re-visit the services, pass on positive messages to others, and continue the use of a particular FP method. On the other hand, dissatisfied clients are more likely to share their negative experiences with others and less likely to return or continue the use of FP services [2].

Improving the quality of services has an impact on women's satisfaction with the services, which may also lead to increased service utilization, continued FP use, achievement of fertility goals, higher contraceptive prevalence rate and low fertility rate [3].

Patient's feedback is necessary to identify problems that need to be resolved in improving the health services. Measuring patient satisfaction depends on using the "accurate measures because it comprises of standards that incorporate dimensions of technical, interpersonal, social, and moral aspects of care" [11].

Contraception is an important issue for all couples, and the method used should be decided by the women and her partner jointly. This process is facilitated by establishing a trusting relationship with the client and by providing unbiased, accurate information about all methods 
available. Adequate communication enhances family planning acceptance, client satisfaction, as well as effective and continued use of contraception [10].

FP positively contributes to the reduction of maternal deaths. It has been estimated that the uptake of contraception in countries with high birth rates has the potential to prevent up to $32 \%$ of maternal deaths and nearly $10 \%$ of infant deaths [6].

One of the main contributions of the International Conference on Population and Development held in Cairo in 1994 was the recognition that satisfaction of sexual and reproductive rights is a human rights issue. This conference led to a global effort to recognize the importance of FP within maternal and child health programs as a mechanism to improve the accessibility and availability of modern contraceptive methods [6].

\section{Aim of the Study}

The present study aimed to assess the satisfaction level of women with family planning services provided at Maternal and Child Health centers.

\section{Subject and Methods}

The descriptive cross-sectional study design was used. The study took place at the four $\mathrm{MCH}$ centers in Assiut city; El Arbeen, Qulta, El Waleed and Hee Gharb. These centers provide both preventive services as; family planning, antenatal care, vaccination) and curative services (Medical care services, investigations...etc) for 6 days a week. These services cover Assiut city and its neighbor villages.

The study population was all married women aged 1549 years and attending the previously mentioned health centers seeking family planning services. The sample size was estimated to be 560 using the statistical formula, $\mathrm{P}$ (proportion of women's satisfaction) $=50 \%, \mathrm{Z}=1.96$, $\mathrm{d}=0.05$ and confidence level $\alpha=0.05$. To adjust for sample loss, e.g. from unusable responses, the sample size was increased, 600 women. Interview method was used for data collection. Two tools were used; the first was an interview questionnaire to collect data about (socio-demographic characteristics, pregnancy and labor history, and history of family planning methods use) and causes for attending the center. The second tool was Bruce's key points questionnaire regarding quality in reproductive health which used to assess the women's satisfaction regarding family planning services. The questionnaire includes 6 aspects to be covered by questions: selection of a FP method, the technical skill of service providers, the relationship between service providers and client, consistency, and follow-up, comprehensiveness of service and presenting information to the clients. A total of 30 questions were prepared for all 6 aspects. A Likert scale was used for responses to questions about satisfaction with aspects of services (completely satisfied $=5$, satisfied $=4$, no view $=3$, unsatisfied $=2$, completely unsatisfied $=1$ ) [9]. The women overall satisfaction level was calculated as a high or low satisfaction level. A pilot study was done on $(10 \%$ of the sample size) 60 women representing all chosen $\mathrm{MCH}$ centers, its aim is to test clarity and explore the needed time for every woman to interview, after that the necessary modifications were done, and the pilot study respondents were excluded from the total sample.

An approval letter was taken from the director of Maternal and Child Health Centers in Assiut city to conduct the study. A clear explanation of nature and aim of the study were explained to the women participated in the study, after that, an oral consent was taken from them; after assuring the confidentiality of the information and the right to withdrawn from the study with no effect on the care which provided to them.

\section{Field Work}

The researchers attending one of the previously mentioned $\mathrm{MCH}$ centers every day according to $\mathrm{MCH}$ schedule days for family planning services. A suitable place for conducting the interview was prepared to ensure privacy and comfort of the participants. The full explanation for the questionnaire questions was done, and then the women asked to give a response for the scale that suits their satisfaction about the family planning services in the proper answer place. Each interview took about 30 minutes of the women receiving the service. Data were analyzed using the statistical package for social science (SPSS) version 11.5. Frequencies, percentages, chi-square test were calculated. Probability (P-value) less than 0.05 was considered significant and less than 0.001 was considered highly significant.

\section{Results}

The present findings show that the mean age of the study respondents was $29.38 \pm 6.13$. The majority $72.2 \%$ of them were from urban areas, $72.4 \%$ of them were housewives and around half (47.8\%) of participants and (54\%) of their husbands had achieved a secondary education. A mean number of family members were 4.57 \pm 1.43 . (Table 1)

Concerning participant's pregnancy and labor history; the results reveals that mean number of pregnancy was $3.09 \pm 1.88$, more than three-quarters of the study respondents have more than 4 living children. The majority of them had no history of abortion. (Table 2).

Regarding the current history of contraceptives use; $47.3 \%$ of the participants reported currently using contraceptive methods. The most frequently mentioned contraceptive method used was IUD (41.6\%) followed by oral pills $(33.5 \%)$. The mean duration of contraceptive use represents $(2.22 \pm 2.15)$. (Table 3 )

As regards to the reason for $\mathrm{MCH}$ visit, it was observed that more than half $(56.4 \%)$ of the mentioned causes by women was for selection of a method, while $33.7 \%$ reported for follow-up of the currently used method. (Figure 1). 
Table 1. Distribution for socio-demographic characteristics of the study participants seeking family planning services, Assiut city

\begin{tabular}{|c|c|c|}
\hline & No. $(n=569)$ & $\%$ \\
\hline \multicolumn{3}{|l|}{ Age: } \\
\hline$<25$ years & 120 & 21.1 \\
\hline $25-<30$ years & 205 & 36.0 \\
\hline$\geq 30$ years & 244 & 42.9 \\
\hline Mean \pm SD (Range) & \multicolumn{2}{|c|}{$29.38 \pm 6.13$} \\
\hline \multicolumn{3}{|l|}{ Residence: } \\
\hline Rural & 158 & 27.8 \\
\hline Urban & 411 & 72.2 \\
\hline \multicolumn{3}{|l|}{ The level of education: } \\
\hline Illiterate & 107 & 18.8 \\
\hline Read \& write & 41 & 7.2 \\
\hline Primary & 25 & 4.4 \\
\hline Preparatory & 20 & 3.5 \\
\hline Secondary & 272 & 47.8 \\
\hline University & 104 & 18.3 \\
\hline \multicolumn{3}{|l|}{ Occupation: } \\
\hline Working & 157 & 27.6 \\
\hline Housewife & 412 & 72.4 \\
\hline \multicolumn{3}{|l|}{ Husband education: } \\
\hline Illiterate & 72 & 12.7 \\
\hline Read \& write & 41 & 7.2 \\
\hline Primary & 18 & 3.2 \\
\hline Preparatory & 18 & 3.2 \\
\hline Secondary & 307 & 54.0 \\
\hline University & 113 & 19.9 \\
\hline \multicolumn{3}{|l|}{ Family income: } \\
\hline$<600 \mathrm{LE}$ & 102 & 17.9 \\
\hline $600-800$ LE & 256 & 45.0 \\
\hline$>800 \mathrm{LE}$ & 211 & 37.1 \\
\hline Mean \pm SD (Range) & \multicolumn{2}{|c|}{$945.32 \pm 708.26(200-7000)$} \\
\hline \multicolumn{3}{|l|}{ Number of family members: } \\
\hline$<4$ & 136 & 23.9 \\
\hline $4-5$ & 292 & 51.3 \\
\hline$>5$ & 141 & 24.8 \\
\hline Mean \pm SD (Range) & \multicolumn{2}{|c|}{$4.57 \pm 1.43(1-10)$} \\
\hline
\end{tabular}

Table 2. Percentage distribution for pregnancy and labor history of the study participants seeking family planning services, Assiut city

\begin{tabular}{|c|c|c|}
\hline & No. $(n=569)$ & $\%$ \\
\hline \multicolumn{3}{|c|}{ Number of pregnancies: } \\
\hline$<4$ & 364 & 64.0 \\
\hline $4-5$ & 151 & 26.5 \\
\hline$>5$ & 54 & 9.5 \\
\hline Mean \pm SD (Range) & \multicolumn{2}{|c|}{$3.09 \pm 1.88(1-16)$} \\
\hline \multicolumn{3}{|c|}{ Number of living children: $\square$} \\
\hline$<4$ & 427 & 75.0 \\
\hline $4-5$ & 125 & 22.0 \\
\hline$>5$ & 17 & 3.0 \\
\hline Mean \pm SD (Range) & \multicolumn{2}{|c|}{$2.67 \pm 1.38(1-10)$} \\
\hline \multicolumn{3}{|c|}{ Number of abortions: $\square$} \\
\hline None & 439 & 77.2 \\
\hline $1-2$ & 110 & 19.3 \\
\hline$>2$ & 20 & 3.5 \\
\hline \multicolumn{3}{|c|}{ Status of previous pregnancy: } \\
\hline Normal & 550 & 96.7 \\
\hline With complications & 19 & 3.3 \\
\hline \multicolumn{3}{|l|}{ Baby status: } \\
\hline Normal & 564 & 99.1 \\
\hline With health problems & 5 & 0.9 \\
\hline
\end{tabular}

Table 3. Percentage distribution for current contraceptive methods used by study participants

\begin{tabular}{|l|c|c|}
\hline Item & No. (n= 569) & $\%$ \\
\hline Current use of contraception: & 269 & 47.3 \\
\hline Yes & 300 & 52.7 \\
\hline No & 112 & 41.6 \\
\hline Type of currently used contraceptive methods: & 33.5 \\
\hline IUD & 90 & 16.7 \\
\hline Oral pills & 45 & 8.2 \\
\hline Injection & 22 & 10.4 \\
\hline Others & 28 & 61.0 \\
\hline Duration of contraceptive use: & 164 & 28.6 \\
\hline$<1$ year & 77 & 18 years $)$ \\
\hline 1 - 2 years & $2.22 \pm 2.15(1$ month -1 \\
\hline$>2$ years & \multicolumn{2}{|c|}{} \\
\hline Mean \pm SD (Range) & \multicolumn{2}{|c|}{} \\
\hline
\end{tabular}

Table 4 shows the results of women satisfaction regarding family planning method and service provider skills. The vast majority $(90.9 \%)$ of women reported satisfaction (completely satisfied or satisfied) that their FP choice was free and informed and $85.1 \%$ of the women reported completely satisfied or satisfied that all FP methods were explained to them, while $4.6 \%$ of them were completely unsatisfied or unsatisfied. As regard to provider skills, the majority $90.5 \%$ of women being completely satisfied or satisfied with the provider experience.

Concerning the Communication skills with health care providers, $86.6 \%$ of the women were completely satisfied and satisfied with the item" felt able to ask questions" and $92.8 \%$ of them were completely satisfied and satisfied with the item" consultation was easy and understandable". Regarding consistency and follow-up, $90.5 \%$ of the women were completely satisfied and satisfied with the item" Would like to come to this center again". (Table 5).

The findings revealed that $72.6 \%$ of women had satisfaction (satisfied or completely satisfied) with the vaccination services and more than three quarters $(76.8 \%)$ of women were satisfied or completely satisfied with the antenatal services. As regard to the information given to the clients' aspect, $86.6 \%$ of the women were satisfied or completely satisfied with the information they received about use of chosen method, while $8.4 \%$ were unsatisfied or completely unsatisfied about information provided from pamphlets and booklets. (Table 6)

Concerning the respondent's total satisfaction score with family planning services, the findings revealed a high satisfaction level among the six aspects and with a total mean score of satisfaction $(140.83 \pm 15.54)$ (Table 7).

Table 8 shows the relation between socio-demographic characteristics (age, family income and a number of deliveries) and aspects of family planning satisfaction. A highly statistically significant difference was found between aspects of (skills of health care provider, communication skills of health care providers, follow-up services and information given to the client and number of deliveries.

Table 9 shows a highly significant relation was found between respondents' age, residence and number of family members and the total satisfaction score. 


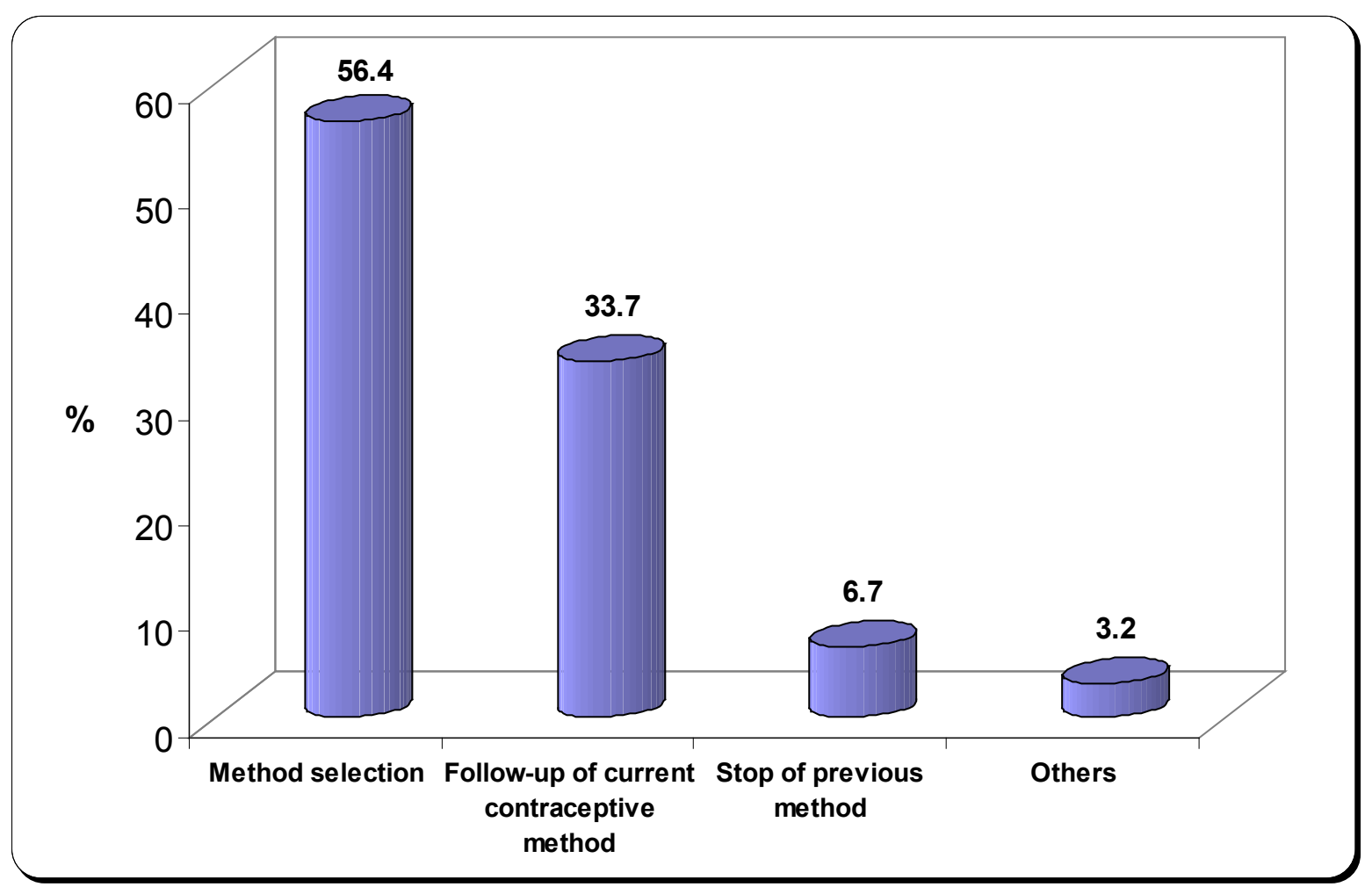

Figure 1. Reasons for current $\mathrm{MCH}$ visit

Table 4. Women satisfaction with: informed choice of family planning method and provider skill.

\begin{tabular}{|c|c|c|c|c|c|c|c|c|c|c|}
\hline & \multicolumn{2}{|c|}{ Very satisfied } & \multicolumn{2}{|c|}{ Satisfied } & \multicolumn{2}{|c|}{ Neutral } & \multicolumn{2}{|c|}{ Dissatisfied } & \multicolumn{2}{|c|}{ Very dissatisfied } \\
\hline & No. & $\%$ & No. & $\%$ & No. & $\%$ & No. & $\%$ & No. & $\%$ \\
\hline \multicolumn{11}{|l|}{ Method selection: } \\
\hline 1) Choice of method was free and informed. & 202 & 35.5 & 315 & 55.4 & 31 & 5.4 & 13 & 2.3 & 8 & 1.4 \\
\hline 2) Identify all FP methods. & 175 & 30.8 & 320 & 56.2 & 61 & 10.7 & 10 & 1.8 & 3 & 0.5 \\
\hline 3) FP methods were explained. & 177 & 31.1 & 307 & 54.0 & 59 & 10.4 & 22 & 3.9 & 4 & 0.7 \\
\hline 4) Information about other settings provides FP services. & 121 & 21.3 & 302 & 53.1 & 98 & 17.2 & 39 & 6.9 & 9 & 1.6 \\
\hline 5) Information about limitations of contraceptive methods. & 144 & 25.3 & 312 & 54.8 & 88 & 15.5 & 20 & 3.5 & 5 & 0.9 \\
\hline 6) Information about other settings referred to in need services. & 121 & 21.3 & 281 & 49.4 & 121 & 21.3 & 25 & 4.4 & 21 & 3.7 \\
\hline \multicolumn{11}{|l|}{ Skills of health care providers: } \\
\hline Provider selected by client & 289 & 50.8 & 108 & 19.0 & 89 & 15.6 & 41 & 7.2 & 42 & 7.4 \\
\hline Knowledge of provider & 373 & 65.6 & 126 & 22.1 & 65 & 11.4 & 5 & 0.9 & 0 & 0.0 \\
\hline Experience of provider & 379 & 66.6 & 136 & 23.9 & 52 & 9.1 & 2 & 0.4 & 0 & 0.0 \\
\hline Promptness of provider & 383 & 67.3 & 129 & 22.7 & 54 & 9.5 & 3 & 0.5 & 0 & 0.0 \\
\hline Skillfulness of provider & 383 & 67.3 & 127 & 22.3 & 56 & 9.8 & 3 & 0.5 & 0 & 0.0 \\
\hline
\end{tabular}

Table 5. Women satisfaction with: interpersonal relationship and consistency and follow- up

\begin{tabular}{|c|c|c|c|c|c|c|c|c|c|c|}
\hline \multirow{2}{*}{ Item } & \multicolumn{2}{|c|}{ Very satisfied } & \multicolumn{2}{|c|}{ Satisfied } & \multicolumn{2}{|c|}{ Neutral } & \multicolumn{2}{|c|}{ Dissatisfied } & \multicolumn{2}{|c|}{ Very dissatisfied } \\
\hline & No. & $\%$ & No. & $\%$ & No. & $\%$ & No. & $\%$ & No. & $\%$ \\
\hline \multicolumn{11}{|l|}{ Communication skills with health care providers: } \\
\hline 1) Felt able to ask questions & 309 & 54.3 & 184 & 32.3 & 67 & 11.8 & 9 & 1.6 & 0 & 0.0 \\
\hline 2) Behavior of provider was polite & 387 & 68.0 & 143 & 25.1 & 37 & 6.5 & 2 & 0.4 & 0 & 0.0 \\
\hline $\begin{array}{l}\text { 3) Had confidence in provider was asked about problems } \\
\text { and aim of FP. }\end{array}$ & 320 & 56.2 & 205 & 36.0 & 42 & 7.4 & 2 & 0.4 & 0 & 0.0 \\
\hline 4) The consultation was easy and understandable. $\square$ & 327 & 57.5 & 201 & 35.3 & 40 & 7.0 & 1 & 0.2 & 0 & 0.0 \\
\hline 5) Consultation used educational tools. & 300 & 52.7 & 200 & 35.1 & 51 & 9.0 & 8 & 1.4 & 10 & 1.8 \\
\hline \multicolumn{11}{|l|}{ Consistency \&Follow-up } \\
\hline 1) FP methods are always available in health centers. & 175 & 30.8 & 299 & 52.5 & 69 & 12.1 & 23 & 4.0 & 3 & 0.5 \\
\hline 2) Have enough information about follow-up. & 159 & 27.9 & 331 & 58.2 & 66 & 11.6 & 10 & 1.8 & 3 & 0.5 \\
\hline $\begin{array}{l}\text { 3) Follow-up by health center knows where to go when } \\
\text { side-effects occur. }\end{array}$ & 157 & 27.6 & 332 & 58.3 & 64 & 11.2 & 12 & 2.1 & 4 & 0.7 \\
\hline 4) Would like to come to this center again. & 177 & 31.1 & 338 & 59.4 & 49 & 8.6 & 3 & 0.5 & 2 & 0.4 \\
\hline 5) Would be supported and guided if side-effects occur & 169 & 29.7 & 337 & 59.2 & 50 & 8.8 & 10 & 1.8 & 3 & 0.5 \\
\hline
\end{tabular}


Table 6. Women satisfaction with: comprehensiveness and information given to clients

\begin{tabular}{|c|c|c|c|c|c|c|c|c|c|c|}
\hline & \multicolumn{2}{|c|}{ Very satisfied } & \multicolumn{2}{|c|}{ Satisfied } & \multicolumn{2}{|c|}{ Neutral } & \multicolumn{2}{|c|}{ Dissatisfied } & \multicolumn{2}{|c|}{ Very dissatisfied } \\
\hline & No. & $\%$ & No. & $\%$ & No. & $\%$ & No. & $\%$ & No. & $\%$ \\
\hline \multicolumn{11}{|l|}{ Comprehensive services: } \\
\hline 1) Monitoring of child growth. & 102 & 17.9 & 271 & 47.6 & 150 & 26.4 & 14 & 2.5 & 32 & 5.6 \\
\hline 2) Child immunization services. & 134 & 23.6 & 279 & 49.0 & 125 & 22.0 & 8 & 1.4 & 23 & 4.0 \\
\hline 3) Antenatal care services. & 142 & 25.0 & 295 & 51.8 & 110 & 19.3 & 5 & 0.9 & 17 & 3.0 \\
\hline 4) Provider explains methods. & 159 & 27.9 & 318 & 55.9 & 82 & 14.4 & 4 & 0.7 & 6 & 1.1 \\
\hline 5) Service provider explain the chosen method & 177 & 31.1 & 321 & 56.4 & 69 & 12.1 & 1 & 0.2 & 1 & 0.2 \\
\hline 6) Provide information about missing pills or side effects. & 163 & 28.6 & 331 & 58.2 & 72 & 12.7 & 2 & 0.4 & 1 & 0.2 \\
\hline 7) Do you obtain your information from booklets or prints? $\square$ & 90 & 15.8 & 268 & 47.1 & 148 & 26.0 & 26 & 4.6 & 37 & 6.5 \\
\hline \multicolumn{11}{|l|}{ Information was given to the client: } \\
\hline 1) All preventive methods. & 139 & 24.4 & 298 & 52.4 & 102 & 17.9 & 24 & 4.2 & 6 & 1.1 \\
\hline 2) Use of chosen method. & 160 & 28.1 & 333 & 58.5 & 73 & 12.8 & 0 & 0.0 & 3 & 0.5 \\
\hline 3) Choice of a method. & 159 & 27.9 & 321 & 56.4 & 79 & 13.9 & 6 & 1.1 & 4 & 0.7 \\
\hline 4) Problems of forgotten pills and side-effects. & 115 & 20.2 & 324 & 56.9 & 111 & 19.5 & 10 & 1.8 & 9 & 1.6 \\
\hline 5) Pamphlets and booklets, side-effects of chosen method. & 114 & 20.0 & 303 & 53.3 & 104 & 18.3 & 27 & 4.7 & 21 & 3.7 \\
\hline 6) Side effects of the chosen method. & 140 & 24.6 & 329 & 57.8 & 83 & 14.6 & 6 & 1.1 & 11 & 1.9 \\
\hline
\end{tabular}

Table 7. Total satisfaction score

\begin{tabular}{|c|c|c|c|}
\hline & Score & Mean \pm SD & Range \\
\hline Method selection & 30 & $24.13 \pm 3.45$ & $10.0-30.0$ \\
\hline Skills of health care providers & 25 & $22.21 \pm 3.49$ & $9.0-25.0$ \\
\hline Communication skills of health care providers & 25 & $22.34 \pm 2.97$ & $11.0-25.0$ \\
\hline Follow-up services & 25 & $20.66 \pm 3.02$ & $5.0-25.0$ \\
\hline Comprehensive services & 35 & $27.54 \pm 3.62$ & $17.0-35.0$ \\
\hline Knowledge for client & 30 & $23.94 \pm 3.74$ & $6.0-30.0$ \\
\hline Total score of satisfaction & 170 & $140.83 \pm 15.54$ & $69.0-170.0$ \\
\hline
\end{tabular}

Table 8. Correlation between satisfaction and demographic characteristics

\begin{tabular}{|l|c|c|c|c|c|c|}
\hline \multirow{2}{*}{} & \multicolumn{2}{|c|}{ Age (years) } & \multicolumn{2}{c|}{ Family income (LE) } & \multicolumn{2}{c|}{ No. of deliveries } \\
\cline { 2 - 7 } & r-value & P-value & r-value & P-value & r-value & P-value \\
\hline Method selection & -0.048 & 0.255 & 0.001 & 0.984 & -0.128 & $0.002^{*}$ \\
\hline Skills of health care providers & -0.060 & 0.150 & -0.104 & $0.013^{*}$ & -0.150 & $0.000^{*}$ \\
\hline Communication skills of health care providers & -0.124 & $0.003^{*}$ & -0.141 & $0.001^{*}$ & -0.195 & $0.000^{*}$ \\
\hline Follow-up services & -0.069 & 0.099 & -0.098 & $0.019^{*}$ & -0.151 & $0.000^{*}$ \\
\hline Comprehensive services & -0.078 & 0.063 & -0.159 & $0.000^{*}$ & -0.125 & $0.003^{*}$ \\
\hline Information was given to client & -0.052 & 0.215 & -0.077 & $0.065^{*}$ & -0.152 & $0.000^{*}$ \\
\hline Total score of satisfaction & -0.092 & $0.028^{*}$ & -0.125 & $0.003^{*}$ & -0.194 & $0.000^{*}$ \\
\hline
\end{tabular}

Table 9. Satisfaction score according to personal characteristics

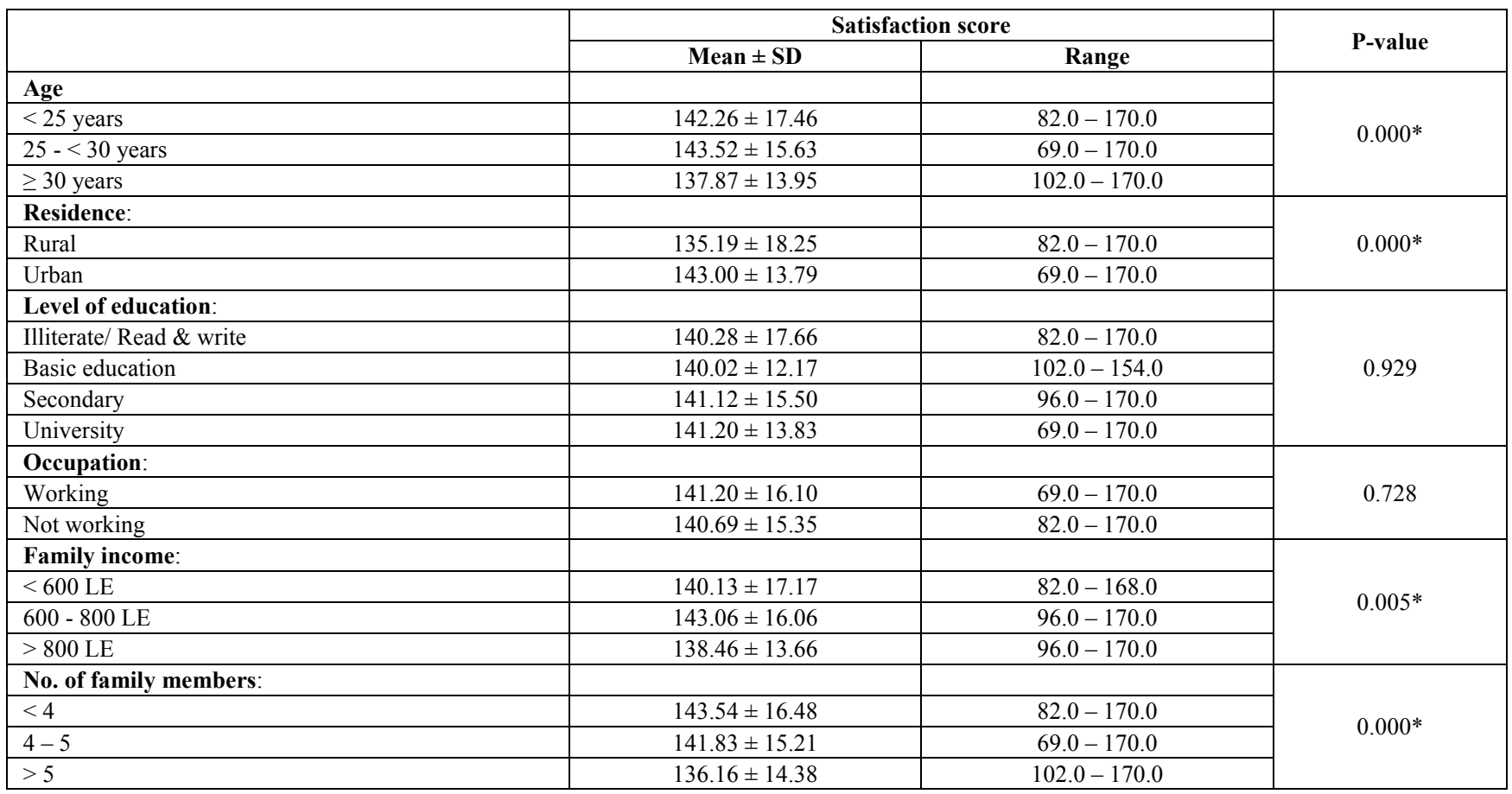




\section{Discussion}

One of the important factors that influence the use of family planning \& other reproductive health services is client satisfaction with health care services [6].

Research's finding in some areas of Sub- Sahara Africa confirms that the importance of waiting time, friendliness of staff, women's education and distance to health facilities as the main determinants of client satisfaction [8].

Results of the current study showed that the majority of the study respondents were from urban areas and housewives. More than half of them complete a secondary education.

Regarding the current uses of contraceptive methods, around half of the participants currently using a contraceptive method, the most frequently reported used methods were the intrauterine device (IUD) and oral contraceptive pills (OCP). Most of the participants visiting $\mathrm{MCH}$ for selection of new family planning method or follow-up the currently used method.

The study results revealed that the majority of women seeking family planning services in Assiut City are satisfied overall with the quality of services they received in different health care centers. These findings reflect that the Ministry of Health and Population doing its best for improving the quality of family planning services.This finding agreed with what has been observed in a study conducted in Urmia University of Medical Sciences to assess women's satisfaction with the reproductive health services, the assessment of women's overall satisfaction indicated that $76.2 \%$ were satisfied and $15.8 \%$ were completely satisfied by services they received [9]. Another study conducted in Hossana Town revealed that $74.3 \%$ of clients were satisfied with the service [3].

Choice of a method has been reported as a very important contributions factor to client satisfaction. The current study findings revealed that most of the respondents reported satisfaction with the method selection and with those methods of family planning were given for them free. This finding reflects the effort which conducted by Ministry of Health to provide the health care centers by different family planning methods free.

Also, this findings supported by that reported by Abdel-Tawab et al., [1] who conduct a study to investigate if the public health services in Egypt help young married women exercise their reproductive rights or not, they reported that the most widely used method is available in the different health centers which an important factor for client's satisfaction.

Individuals require adequate information and a range of options to make the suitable decisions about family planning, the current study revealed that fast majority of women were satisfied with the choice of family planning method, and the detailed information which given to them about every method. The same finding reported by Wood et al., [13] who assess Patient's experiences with family planning in Community Health Centers in Columbia, they find that the studied women reported general satisfaction with the information they received in the centers about family planning methods, regardless of the source of information or the source of care, also Nanbakhsh et al., [9] reported almost all the women (93.3\%) indicated satisfaction (completely satisfied or satisfied) that their choice of FP method was free and informed.
The current study results also show that one-quarter of the respondents unsatisfied about information was given to them about the method, this may be due to overloading of work and increase number of clients with limited time because centers provide other reproductive and vaccination service. Similar results have been reported by Chavane et al., [6] who studied women's satisfaction with family planning services in Mozambique, they reported that the women are completely satisfied with the family planning services provided to them at different health care facilities.

As regard providers' skill, the majority of women reported satisfaction with provider's skills and their experiences.

Concerning the communication skills with health care providers, most of the women were satisfied and completely satisfied. This ensures the health care providers capability of work closely with their clients and emphasizes good communication skills. This result confronted with that reported by Rehman et al., [11] who conduct a study in Jinnah hospital, Lahore to assess client satisfaction regarding F.P Services in Reproductive Center; that $(61.5 \%)$ of the clients were unsatisfied and $(19.8 \%)$ were highly unsatisfied with the ability of health care provider.

The majority of women are satisfied with quality and adequacy of counseling they are received at the centers and they show their desire to continue to visit the same center to receive other family planning and reproductive services. They also reported that they are satisfied with other services which provided as antenatal care and vaccination, this reflect that the quality and complicity of service is very important for clients to continue for receiving not only family planning service but other reproductive health services, also reflect the successful vision of the Ministry of Health in cover all areas with reproductive and neonatal health service. In the same line of this finding, Nasr and Hassan [10], who are perform study to explore the association between quality of family planning services and client's satisfaction level in maternal and child health centers in Port Said city, they reported that the majority of the clinics are satisfactory about family planning services.

The current study reflects that near to three-quarter of women are satisfied with information which given to them about the currently used method. This finding agreed with that reported by, Nanbakhsh et al., [9] that the majority of women $(88.3 \%)$ had high satisfaction (completely satisfied and satisfied) with information they received about the use of their chosen FP method.

The current study reflects that more than one-quarter of them are not satisfied with the giving pamphlet and booklet which include side effect about the currently chosen method, this may be due to decrease education level of women. This result in conjunction with that reported by Nanbakhsh et al., [9] that level of dissatisfaction level related to the method of counseling; they reported in their study; one-third of women $(32.3 \%)$ were unsatisfied or completely unsatisfied with the item about the distribution of information from pamphlets and booklets.

As regard to total clients' satisfaction score, most of the women are satisfied with comprehensive of the service, selection of the method and providers skills and communication. 
Regarding the correlation between women's satisfaction and their demographic characteristics, the study reflects a significant correlation between women's satisfaction and the number of deliveries, family income, and women's age. This finding agreed with that reported by Argago et., al. [3], who conduct a study to assess the client's satisfaction with family planning services and associated factors in Hossana Town Public Health Facilities, they reported a statistically significant association between age, the number of parity of clients with family planning service satisfaction. The current study reflects a statistical correlation between women's age, residence, family income and the number of the family member and total level of women's satisfaction with family planning services.

\section{Conclusion}

Based on study findings, it was proved that the most of maternal \& child health care centers have good quality level in health services organization, facilities available in the clinics. Significantly, the majorities of the clients were satisfied with the provided skills and counseling about different family planning methods, and have the intention to revisit the clinic in the future. In addition, it was proved from the study that the factors affecting client satisfaction were number of parity, family income; it is observed also that the health care provider being an important factor in women's satisfaction.

\section{Recommendation}

Based on the present study findings, the following was recommended:

1. Family planning providers require training to strengthen their communication skills so that they can meet their client's individual needs. Their training should also include involving men in family planning decisions and practices.

2. Further prospective studies to determine factors affecting client satisfaction should be conducted.

3. The fact that women value and depend on health centers for family planning care serves to further emphasize the importance of engaging in quality improvement efforts in order to further strengthen the client experience.

\section{References}

[1] Abdel-Tawab N., Rabie T., Boehmova Z., Hawkins L., Saher S., and El Shitany A. (2015). Do public health services in Egypt help young married women exercise their reproductive rights? International Journal of Gynecology and Obstetrics 130: E52-E55.

[2] Agwanda A. Kimani AKM (2009). Assessment of family planning services in Kenya: Evidence from the 2004 Kenya Service Provision Assessment Survey. Nairobi. pp.1-51.

[3] Argago T. G., Hajito K. W., and Kitial S. B. (2015). Clint's satisfaction with family planning services and associated factors among family planning users in Hossana Twon Public Health Facilities, South Ethiopia: Facility- based cross- sectional study. International journal of Nursing and Midwifery, vol. 7(5): 74-83.

[4] Bongaarts J, (2011). Can family planning programs reduce high desired family size in Sub-Sahara Africa? International Perspectives on Sexuality \& Reproductive Health. 37(4): 209-216.

[5] Bruce J. Fundamental elements of the quality of care: a simple framework. Studies in family planning, 1990, 21(2): 61-91.

[6] Chavane L., Dgedge M., Baily P., Loquiha O., Aerts M., \& Temmerman M., (2016). Assessing women's satisfaction with family planning services in Mozambique. J family \& reproductive health care. November: 1-7. Child health centers in Port Said city. Journal of Nursing Education and practice.

[7] Donabedian A. The quality of care: How can it be assessed? Journal of American medical association. 1998; 260(12): 1743-1748.

[8] Maseko F., Chirwa M, Muula A. (2014) client satisfaction with cervical cancer screening in Malawi. BMC Health Serv Res; 14: 220.

[9] Nanbakhsh H, Salarilak S, Islamloo F, Aglemand S. (2008). Assessment of women's satisfaction with reproductive health services in Urmia University of Medical Sciences. Eastern Mediterranean Health Journal, 14 (3): 605-614

[10] Nasr E. H., \& Hassan H. E., (2016). Association between quality of family planning services and client's satisfaction level in maternal and Practice. Vol. 6(1): 85-99.

[11] Rehman F., Janjua A. R. and Shahzad H (2015). Client Satisfaction Regarding Family Planning Services in Reproductive Center at Jinnah Hospital, Lahore. P J M H S Vol. 9 (3), 1048- 1050.

[12] Tumlison K, Pence W, B, Curtis S, L, Marshall S, W, and Speizer I, S. (2015). Quality of care \& contraceptive use in urban Kenya. International Perspectives on sexuality \& reproductive Health. Vol 41(2): 69-79.

[13] Wood S. F., Beeson T., Goldberg D.G., Katherine H. M., Shin P., Abdul-Wakil A., Rui A., Sahgal B., Shimony M., Stevens H., and Rosenbaum S. (2015). Patient Experiences With Family Planning in Community Health Centers. Geiger Gibson/RCHN Community Health Foundation Research Colla. 